\title{
General trust scale: Validation in cross-cultural settings
}

\author{
Dorota Jasielska $^{1}$ (D) $\cdot$ Radosław Rogoza ${ }^{2} \cdot$ Anna Zajenkowska $^{1} \cdot$ Mary Bower Russa $^{3}$
}

Published online: 12 September 2019

(C) The Author(s) 2019

\begin{abstract}
Trust plays a critical role in all aspects of social functioning. In attempting to better understand trust cross culturally, a valid tool is essential. We conducted two studies to investigate the cross-cultural validity and utility of the Generalized Trust Scale (Yamagishi and Yamagishi 1994). In Study 1, the structural and convergent validity of the GTS was examined in a large Polish sample $(N=$ 727). Our findings provided important preliminary evidence for the validity of this scale in this sample. Subsequently, Study 2 compared responses to the GTS from two culturally different countries: Poland $(N=203)$ and the United States $(N=230)$. The structure of the GTS remained invariant across these two cultures, and the level of trust was comparable. As expected Americans showed higher levels of happiness than Poles, yet the relationship between trust and happiness was positive and similar in strength for both countries. Our data provide preliminary support for the use of the GTS in cross-cultural comparisons; however, consideration of data at the item level may also be relevant and cross culturally useful.
\end{abstract}

Keywords Trust $\cdot$ Happiness $\cdot$ Big five $\cdot$ Poland $\cdot$ United States

\section{Introduction}

Trust is a core element of everyday interactions and is crucial for the macro and micro level of social functioning (Helliwell 2006; Putnam 2000). It would be impossible to maintain satisfying relationships or conduct most business transactions without this social lubricant. Trust has been defined as a willingness to be vulnerable to the actions of others (Mayer et al. 1995). Therefore, propensity to trust is related to the expectation of positive rather than negative outcomes of the actions of others (Ashraf et al. 2006; Johnson and Mislin 2011; Yamagishi and Yamagishi 1994). Trust arises from social attitudes regarding the world and other people. These attitudes can be developed in two contexts: global, where they reflect a general approach to society; and interpersonal, where they concern everyday interactions (Putnam 2000).

Dorota Jasielska

djasielska@aps.edu.pl

1 Institute of Psychology, Maria Grzegorzewska University, Szczęśliwicka 40, 02-353 Warsaw, Poland

2 Institute of Psychology, Cardinal Stefan Wyszyński University, Warsaw, Poland

3 Psychology Department, Grand Valley State University, Allendale, MI, USA
General, or 'depersonalized trust', is essential for any economic exchange, as well as for social cooperation. This type of trust often manifests as trust towards public institutions or outgroup members (Maddux and Brewer 2005), and it is essential for building egalitarian systems and creating a prosperous society (Helliwell et al. 2016; Tov and Diener 2008). The world has seen a political shift to more nationalistic values over the past decade (Inglehart and Norris 2016), and this change has been associated with increased fear towards out-group members, and the general erosion of social trust in both Europe (Mungiu-Pippidi et al. 2015) and in the United States (Edelman 2018).

Past research illustrates a connection between trust and favorable national outcomes, such as economic growth and earnings, as well as between trust and a variety of desirable interpersonal qualities (e.g., social solidarity, tolerance, volunteerism, donation to charity, cooperation, optimism; Ashraf et al. 2006; Rothstein and Uslaner 2005; Tov and Diener 2008). In fact, large sample studies have found that trust is strongly associated with the quality of agreeableness (Digman 1990; Evans and Revelle 2008), and trust is one of the agreeableness facets in the recent development of the new Big Five Inventory (Soto and John 2017). In contrast, a negative association between trust and neuroticism has been reported, perhaps because holding negative beliefs about others is associated with experiencing unpleasant emotions (Soto and John 2017). In sum, trust is associated with both national and subjective well-being (Helliwell et al. 2016; Jasielska 2018; Tov and Diener 2008). 
Research provides evidence for a relationship between trust and happiness on both individual and national scales. Trust is considered one of the major cultural features that facilitates national happiness (Tov and Diener 2008; Triandis 2000), and it is a hallmark of the happiest countries in the world such as Denmark, Norway, and Iceland (Helliwell et al. 2018). High levels of trust may lead to higher levels of national happiness via associations with other determinants of happiness, such as positive attitudes towards institutions and other people, more frequent experience of positive emotions, increased quality of social relations, and increased levels of tolerance and kindness (Growiec and Growiec 2014; Jasielska 2018; Rothstein and Uslaner 2005). The impact of trust on social relationships is far reaching: trust critically influences a range of interpersonal and intergroup interactions, including those involved in both organizational and economic settings (Evans and Revelle 2008; Montoro et al. 2014).

Understanding cross-cultural variation in trust is particularly important, as it may ultimately lead to improved understanding of cross cultural variation in happiness and some of the more specific mechanisms by which happiness ultimately derives. Cross-cultural differences in happiness have been ascribed to many social factors, including: cooperation, frequency of volunteerism, democratic attitudes, social equality and security, strong relationships between clerks and citizens, public institutions that function properly, and most notably, a high level of social trust (Tov and Diener 2008; Triandis 2000). Because low levels of trust negatively influence both subjective well-being and a society's social capital and resilience in response to crises (Helliwell et al. 2016; Putnam 2000; Tov and Diener 2008), improved understanding of trust and happiness cross-culturally is warranted (Fukuyama 2001; Fukuyama 1995).

Exploration of the determinants and impacts of trust requires a measure with demonstrated validity with regard to associations with social behavior and well-being. Furthermore, identification of a measure with cross cultural validity is critical in facilitating research on trust by potentially allowing more consistency in measurement of trust cross culturally and by ultimately allowing for key cross-cultural comparisons that may increase understanding of cultural impacts on trust. For example, in countries like Poland (Eastern Europe), where there is a low level of social capital and limited willingness to engage in citizenship behaviors, trust towards strangers remains at a very low level (Czapinski and Panek 2015). Perhaps for this reason, the level of happiness is also lower than in countries with a higher level of social capital, such as the United States (Helliwell et al. 2016).

Our study aims to address these measurement needs by presenting some initial cross cultural psychometric data regarding a promising instrument to measure trust. Given key demonstrated differences in cultural orientation between Poland and the United States (Schwartz 2006), these countries were chosen for this initial research. Both countries differ substantially in terms of geopolitical location and historical experiences. Based on cultural norms analysis and the personality profiles of citizens, Americans can be described as impulsive, warm and trusting, whereas Poles are more as selfconscious and vulnerable (McCrae and Terracciano 2005; McCrae 2004). Americans are also more oriented towards mastery (i.e., attaining group or personal goals) and less towards the embeddedness and collectivism that is more characteristic in Poland (Schwartz 2006; Hofstede 2001). Thus, exploration of trust in these two populations seemed an appropriate first step in the examination of the cross cultural validity and utility of this instrument.

\section{Measurement of Trust}

The most common techniques to study trust are games and self-reports (Jasielska 2018). Trust games measure the construct of trust in a social context in which the person makes decisions about the allocation of money that is distributed between himself and a stranger (Johnson and Mislin 2011). Trust games, although very promising, pose some interpretational difficulties. It is not always clear how behavior in the game should be interpreted, because it can be influenced by a range of motivations such as risk taking, wish to do "the right thing" or betrayal aversion (Ashraf et al. 2006; Bohnet and Zeckhauser 2004; Butler et al. 2016). Among the self-report measures to study trust three instruments have been extensively studied. The first and most longstanding is the Interpersonal Trust Scale (Rotter 1967). This scale consists of 25 items that deal with trust in general and with trust towards concrete social entities (such as parents, teachers or public officials). Yet, the predictive validity of the scale is limited (Carter and Mark Weber 2010; Evans and Revelle 2008). For example, studies conducted using this instrument have reported that trust was uncorrelated with behavior in economic situations, such as the prisoner's dilemma (Evans and Revelle 2008; Rotter 1971). Another popular measure of trust is a single item from the World Values Survey (asking whether people are generally worth trusting or whether it is better to be careful). The validity of this instrument has been questioned because it is not clear how respondents interpret the question and whether the item measures trust or reflects the average willingness of society to engage in trustworthy behavior (Delhey et al. 2011; Glaeser et al. 2000; Johnson and Mislin 2011). The Generalized Trust Scale (GTS; Yamagishi and Yamagishi 1994) offers a promising alternative to these two instruments because it has been used to successfully study and predict trusting behavior, and it has proven useful in cross-cultural research (Carter and Mark Weber 2010; Montoro et al. 2014; Yamagishi 2001). The GTS is a self-report tool designed to measure trust, defined as an expectation of trustworthiness of others (or high default expectations of human benevolence - 
Yamagishi 2001). In studies with Japanese, Canadian and American samples (Carter and Mark Weber 2010; Yamagishi, Kikuchi \& Kosugi 1999; Yamagishi, 2001) this scale has demonstrated reliability and predictive validity in social contexts that included cooperation and lie detection.

\section{Study 1}

This study investigated the cultural universality of the GTS by initially validating it in a large Polish sample. We examined the structural and convergent validity of the scale in terms of its relation to the Big Five. The Big Five appears to broadly capture individual differences in thinking, feeling and behavior (Goldberg 1990; Soto and John 2017). This measure was deemed appropriate for consideration of convergent validity because it is perhaps one of the most well-known and extensively researched personality instruments (Gosling et al. 2003). In addition, The Big Five shows strong psychometric characteristics and allows assessment of key personality traits in a concise and understandable way (Soto and John 2017). Based on findings in previous research on trust and GTS trust, we expected that in this sample, the structure of the GTS would be unidimensional (Hypothesis 1) and GTS Trust would demonstrate convergent validity via association with high agreeableness (Hypothesis 2). To assess the measurement model of the GTS we conducted a confirmatory factor analysis (CFA). We also examined results of an additional model controlling for common method bias (Podsakoff et al. 2012) through introduction of an uncorrelated single latent factor, for which factor loadings were constrained to be equal. The tested CFA models are illustrated on Fig. 1. To test the hypothesis regarding the relation of trust to the Big Five traits, we ran a series of Structural Equation Models (SEM) in which trust was predicted by basic personality traits. In the evaluation of all CFA and SEM models' fit, we relied on standard fit criteria, i.e., CFI > .900 and RMSEA < .08 (Byrne 1994). In evaluation of the results of Multi-group Confirmatory Factor Analysis (MGCFA) we followed Chen's (2007) recommendations, i.e., the difference in CFI should not exceed .010 and the difference in RMSEA should not exceed .015 between subsequently analyzed models. No correlations between residuals were allowed. These analyses were carried out in Mplus v. 7.2 (Muthen \& Muthen, 2012).

\section{Materials and Methods}

\section{Participants}

Respondents participating in Study 1 were young adults originating from Poland who were between 18 to 35 years of age $(M=22.19 ; S D=2.54 ; 69.9 \%$ females; $100 \%$ Caucasian; $N=$ 727). Data were collected during a three-month period from October to December 2017 using Google Forms platform. Participation was voluntary, and no missing data were allowed (i.e., the form was saved only upon completion). As an incentive, participants were able to join a cash prize draw. All of the participants who volunteered to participate within the study were recruited through local student Facebook groups.

\section{Measures}

\section{Generalized Trust Scale}

The GTS (Yamagishi and Yamagishi 1994; Yamagishi and Kosugi 1999) measures general level of trust $(\alpha=.83)$ in the form of expectation of trustworthiness of others. It consists of six items, which assess belief about people's trustworthiness, such as "Most people are basically honest". Participants responded using five-point Likert scale from 1 (completely disagree) to 5 (completely agree). Prior to use, this scale was translated into Polish and then back translated by a bilingual person.

\section{Big Five Inventory-2}

Personality traits were measured using the 60-item Big Five Inventory-2 (BFI-2; Soto and John 2017). The BFI2 prompts respondents with the phrase "I am someone who..." and asks them to rate themselves on trait-
Fig. 1 Analyzed measurement models of the Generalized Trust Scale with (right) and without (left) method factor
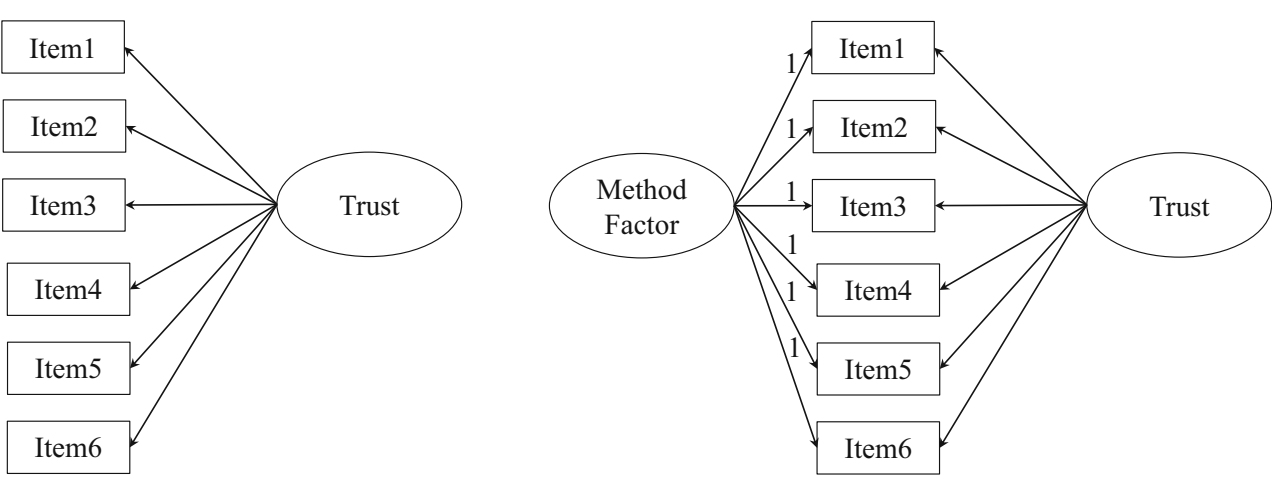
descriptive attributes, such as "often feels sad" (negative emotionality, which is alternatively label neuroticism; $\alpha=.89$ ); "is talkative" (extraversion; $\alpha=.90$ ); "is inventive, finds clever ways to do things" (open-mindedness, which is alternatively labeled openness to experience; $\alpha=.82$ ); "is reliable, can always be counted on" (agreeableness; $\alpha=.82$ ); and "is persistent, works until the task is finished" (conscientiousness). Respondents answered using a five-point Likert-type scale ranging from 1 (disagree strongly) to 5 (agree strongly). Within the BFI-2 it is possible to distinguish facet scales comprised of four items each; however within the current study we analyzed only the domain scales, comprised of twelve items each. Prior to use, this scale was translated into Polish and then back translated by a bilingual person.

\section{Results}

The descriptive statistics and bivariate correlations of analyzed variables within the Study 1 are presented in Table 1.

\section{Verification of the General Trust Scale Structure}

To test the structural validity of the GTS, we conducted two unidimensional CFA models which differed with regard to whether they included the method factor. Both models were fitted to the data; however the introduction of the method factor yielded superior fit $\left(\chi_{(8)}^{2}=27.41\right.$; $p<.001$; CFI $=.986$; RMSEA $=.058[.035-.082])$ in comparison to the raw unidimensional model $\left(\chi_{(9)}^{2}=110.06\right.$; $p<.001 ;$ CFI $=.926$; RMSEA $=.124[.104-.146])$. The standardized factor loadings for both models are presented in Table 2.

The strength of the method factor loadings suggested that they accounted for a significant amount of measurement error. Two out of six items, i.e., Item 3 ("Most people trust a person if the person trusts them") and 5 ("Most people trust others"), for which the initial strength of the factor loading was also the weakest, showed the largest measurement error accounted for by the method factor. Thus, the incorporation of the method factor revealed some structural weaknesses in the measurement of trust which should be controlled.

\section{Test of the Hypothesis Regarding Relation with the Big Five Traits}

To examine concurrent validity for the GTS, we ran a series of SEM models in which trust was predicted by personality traits. The summary of the fit indices for the tested models is presented in Table 3.

With the exception of the agreeableness model, which was close to acceptable fit values, all of the remaining tested models were well-fitted to the data. The lack of fit of the agreeableness model is probably a result of content overlap (trust is one of its facets), as can be noted in the inter-scale correlations of the residuals. Thus, we also analyzed the results of this model. The standardized estimates presenting predictions of trust by personality traits are summarized in Table 4.

Among the personality traits, only Agreeableness was consistently positively predictive of trust. In regard to other traits, negative associations were significant for depression, emotional volatility, assertiveness, and creative imagination. Among the Agreeableness facets, trust as measured by BFI-2 was a stronger predictor of GTS Trust than compassion $(Z=16.26 ; p<.001)$ and respectfulness $(Z=$ $7.24 ; p<.001)$. Thus, the hypothesis regarding the relation of trust to personality traits was supported. These data provide initial support for the convergent and divergent validity for GTS Trust.

\section{Discussion}

The goal of the first study was to examine the structural and convergent validity of the GTS Trust Scale in relation to the Big Five model in a large Polish sample. Among the personality traits, facets of agreeableness (trust, compassion, respectfulness) were the most significant predictors of GTS trust, with BFI-2 Trust being the strongest predictor of GTS Trust. These results are consistent with previous studies (Evans and Revelle 2008; Montoro et al. 2014; Soto and John 2017), and they provide evidence of convergent validity for the GTS. Associations between GTS Trust and other personality traits were also in expected directions. GTS Trust was negatively associated with depression and emotional volatility: a low level of trust may lead to unpleasant emotional states due to ascribing negative intentions to others. The observed negative association of GTS trust with assertiveness and creative imagination is consistent with the notion that trustful people may be willing to pass control to others (Jasielska 2018). This may negate or lessen the need for assertive behavior in the form of taking initiative and being able to influence others (Soto and John 2017).

Although the GTS Trust Scale showed reliability (as in previous studies - Carter and Weber 2010; Montoro et al. 2014), we found that Item 3 ("Most people trust a person if the person trusts them") and Item 5 ("Most people trust others") showed significant measurement error, which weakened the scale structurally. This concern was also partially consistent with reports from the Spanish adaptation of the GTS (Montoro et al. 2014), where Item 3 required removal due to problems with fit. It is important to note that the construction of Items 3 and 5 varies from that of the other scale items in that Items 3 and 5 measure assumptions about trusting people in social interactions, rather than general expectations 
regarding the trustworthiness of others. If these items continue to raise psychometric concerns in other samples, there may be some benefits to scale modification.

\section{Study 2}

Trust in social sciences is closely associated with social capital (Fukuyama 2001, 1995). Social capital in the form of level of trust in a society relates to honesty and the keeping of commitments, both of which can be blocked by distrust (Fukuyama 2001). Interestingly, there are regions in the world (e.g., southern Italy), where the above mentioned virtues are present, but are expressed mostly within the members of their immediate nuclear family and not towards out-group members (Fukuyama 2001). Such a pattern is more common in collectivist societies, where loyalty tends to be directed mainly towards in-groups members, as defined by family, clan, ethnic, or religious membership, for example (Fernández et al. 2005). At the same time trust towards other people is low. Poland is an example of a low-trust society (Delhey and Newton 2005), with very low levels of 'depersonalized trust' (trust toward a relatively unknown other person - Sztompka 1996). In comparison to the US, Poland is more collectivistic and particularistic: seeking resolution based on context, bending rules when necessary, and finding exceptions to convention (Zajenkowska et al. 2013). In particularistic cultures, being an in-group member such as a close friend is a privileged position, and is usually blessed with more trust (HampdenTurner and Trompenaars 1997). On the other hand, large scale value surveys show a pattern where individualistic societies, based on their increased trust towards strangers, are able to create contractual social relations more easily (e.g., the US: Fernández et al. 2005; Hofstede 2001; Smith et al. 1996; Schwartz 1994). In such societies, sense of self tends to be more bounded and stable in ways that make it more independent and resistant to the judgment of others (Singelis and Sharkey 1995). Perhaps this makes it easier to be open towards strangers.

Moreover, in individualistic countries (such as the United States, Australia and the nations of Western Europe) the creation and maintenance of a positive sense of self is a driving force (Markus and Kitayama 1991; Triandis 2000). Studies show that happiness is positively related to individualism and negatively related to collectivism, even when income, human rights and equality are controlled (Basabe and Ros 2005; Diener et al. 1995). This may be because people in individualist countries focus more on their own subjective well-being, whereas members of collectivist cultures prioritize their social image and acceptance by the in-group over the personal pursuit of happiness.

Therefore, the second study tests whether 1) the structure of the GTS is invariant across two different countries representing more collectivist and more individualist cultures (Poland and the United States; Hypothesis 3). As a collectivist country, persons in Poland tend to be more focused on maintaining relationships with the in-group rather than the outgroup, while individuals in the United States are more individualistic and more likely to be open towards strangers. However, this scale has been used previously in countries with different cultural characteristics such as Japan, Canada and Spain (Carter and Weber 2010; Montoro et al. 2014; Yamagishi 2001). Based on this past research, we expected to obtain a similar structure of the scale in Poland and United States.

However, investigation in these two nations also allowed for a more detailed consideration of the psychometric properties of the scale and comparison of any potential discrepancies between these two countries. Again, Poland and United States differ in terms of cultural characteristics, with the former being more collectivistic and focused on maintaining relationships with their in-group rather than the out-group, and the latter being more individualistic and more likely to be open towards strangers. Since the level of trust typically is higher in more individualistic countries (Realo et al. 2008) and countries expressing in-group collectivism tend to be less trustful (Huff and Kelley 2005), we expected that Americans would have higher levels of trust than Poles (Hypothesis 4). Additionally, we examined the ability of trust to predict happiness in Poland and the United States. Consistent with the global data from World Happiness Report, where United States ranks \#18 and Poland ranks \#42 (Helliwell et al. 2018), we expected that
Table 1 Descriptive statistics and bivariate correlations for Trust and BFI-2

\begin{tabular}{llllllll}
\hline & 1. & 2. & 3. & 4. & 5. & $M$ & $S D$ \\
\hline 1. Trust & & & & & & 4.10 & 1.14 \\
2. Extraversion & .07 & & & & 3.09 & 0.84 \\
3. Agreeableness & $.42^{* *}$ & .05 & & & 3.42 & 0.63 \\
4. Conscientiousness & .05 & $.35^{* *}$ & $.20^{* *}$ & & 3.27 & 0.77 \\
5. Negative emotionality & $-.17^{* *}$ & $-.43^{* *}$ & $-.10^{*}$ & $-.30^{* *}$ & & 3.35 & 0.81 \\
6. Open-mindedness & -.04 & $.28^{* *}$ & $.09^{*}$ & $.12^{*}$ & .00 & 3.80 & 0.67 \\
\hline
\end{tabular}

$* p<.01 ; * * p<.001$ 
Table 2 Standardized factor loadings of the General Trust Scale in models with and without the method factor

\begin{tabular}{llll}
\hline & \multirow{2}{*}{ Unidimensional model } & \multicolumn{2}{l}{ Unidimensional model with method factor } \\
\cline { 3 - 4 } & & Trust & Method factor \\
\hline $\mathrm{t} 1$ & .88 & .70 & .55 \\
$\mathrm{t} 2$ & .90 & .74 & .54 \\
$\mathrm{t} 3$ & .46 & .11 & .60 \\
$\mathrm{t} 4$ & .75 & .43 & .62 \\
$\mathrm{t} 5$ & .34 & -.11 & .62 \\
$\mathrm{t} 6$ & .59 & .27 & .54 \\
\hline
\end{tabular}

Americans would score significantly higher on happiness (Hypothesis 5). At the same time, since a relationship between trust and happiness is well documented both on a national (Tov and Diener 2008) and individual (Jasielska 2018) level, we expected that the relation between trust and happiness would be positive and similar in strength in both countries (Hypothesis 6). To test the third, fourth and fifth hypotheses we used multi-group confirmatory factor analysis, and for assessment of the sixth hypothesis, we employed Structural Equation Modeling (SEM).

\section{Materials and Methods}

\section{Participants}

The respondents in Study 2 were adults recruited from two countries: Poland and the United States. Polish participants were 19 to 60 years of age $(M=25.76 ; S D=7.50 ; N=203$; $54.7 \%$ females; $100 \%$ Caucasian) and United States participants were 17 to 36 years of age $(M=18.66 ; S D=1.81 ; N=$ 230; 74.8\% females; $85.2 \%$ Caucasian; $8.3 \%$ Hispanic, $7 \%$ African-American; $3.5 \%$ Asian and $2.1 \%$ other). The Polish sample was significantly older $\left(\chi_{(28)}^{2}=291.33 ; p<.001\right)$ and with more men $\left(\chi_{(2)}^{2}=20.71 ; p<.001\right)$ than the American sample. Polish participants were recruited from Facebook groups for university students and graduates (researchers posted invitations in these groups with a link to the online survey). U.S. students were recruited from Introductory Psychology courses at a regional university. The U.S. students

Table 3 Model fit indices of the analyzed Structural Equation Models

\begin{tabular}{lllll}
\hline & $\chi_{(128)}^{2}$ & CFI & RMSEA & $90 \%$ CI \\
\hline Negative emotionality & 500.85 & .923 & .063 & $.058-.069$ \\
Extraversion & 434.65 & .942 & .057 & $.052-.063$ \\
Open-mindedness & 343.58 & .943 & .048 & $.042-.054$ \\
Agreeableness & 651.23 & .857 & .075 & $.069-.081$ \\
Conscientiousness & 527.26 & .913 & .066 & $.060-.071$ \\
\hline
\end{tabular}

elected to participate in this study as one of a number of options for gaining required research participation credits for their course. All participants completed anonymous surveys via computer.

\section{Measures}

\section{Generalized Trust Scale (as Described in Study 1)}

The reliability estimate for the GTS in Study 2 was good for both the American $(\alpha=.83)$ and the Polish samples $(\alpha=.82)$. For the English version we used Carter and Weber (2010) translation of the scale.

\section{Subjective Happiness Scale}

In order to assess happiness, we used the Subjective Happiness Scale (SHS; Lyubomirsky and Lepper 1999). This scale offers a global subjective assessment of level of personal happiness, and hence, it reflects a broader and more molar category of well-being than measures that focus on specific categories of happiness. In addition, this measure has shown evidence of both convergent and discriminant validity in previous research (Lyubomirsky and Lepper 1999). This scale consists of four items. Two items ask respondents to characterize themselves using both absolute ratings and ratings relative to peers (such as "In general, I consider myself..."; answers from 1 - not a very happy person to 7 a very happy person). The other two present brief descriptions of happy and unhappy individuals (such as "Some people are generally very happy. They enjoy life regardless of what is going on, getting the most out of everything") and ask respondents the extent to which each characterization describes them. Participants responded using a seven-point Likert scale. Reliability estimates were acceptable in both American $(\alpha=.84)$ and Polish samples $(\alpha=.72)$. Prior to use in the Polish sample, this scale was translated into Polish and then back translated by a bilingual person.

\section{Results}

The descriptive statistics and bivariate correlations for Study 2 variables are presented in Table 5 .

\section{Replication of the Structure of the General Trust Scale in Poland and United States}

We began our analyses by replicating the GTS measurement model using independent samples from Poland and the United States (Hypothesis 3). The results suggested that the model with the method factor was well-fitted to the data in both samples (for Poland: $\chi^{2}{ }_{(8)}=15.22 ; p=.055 ; \mathrm{CFI}=.979$; RMSEA $=.067$; and for United States: $\chi^{2}{ }_{(8)}=12.76$; 
Table 4 Standardized regression coefficients from analyzed Structural Equation Models

\begin{tabular}{llllll}
\hline & Negative emotionality & Extraversion & $\begin{array}{l}\text { Open- } \\
\text { mindedness }\end{array}$ & Agreeableness & Conscientiousness \\
\hline Facet 1 & -.08 & .00 & -.11 & $.28^{* * *}$ & -.03 \\
Facet 2 & $-.17^{* * *}$ & $-.16^{* *}$ & -.01 & $.33^{* * *}$ & -.02 \\
Facet 3 & $-.11 *$ & .06 & $-.12^{*}$ & $.50^{* * *}$ & -.02 \\
\hline
\end{tabular}

Negative emotionality facets: anxiety, depression, emotional volatility; Extraversion facets: sociability, assertiveness, energy level; Open-mindedness facets: intellectual curiosity, aesthetic sensitivity, creative imagination; Agreeableness facets: compassion, respectfulness, trust; Conscientiousness facets: organization, productiveness, responsibility

$* p<.05 ; * * p<.01 ; * * * p<.001$

$p=.121 ; \mathrm{CFI}=.987$; RMSEA $=.051)$. The standardized factor loadings from both models are presented in Table 6 .

As in the previous sample, the introduction of the method factor accounted for a notable amount of the measurement error, confirming that controls for this factor were useful. As in the previous study, Items 3 and 5 were most affected by the method bias, with strength of their factor loadings low irrespective of the study sample.

Next, we examined whether the structure of GTS Trust was invariant across the Poland and the United States samples; the results of the MGCFA are reported in Table 7.

Full metric scalar invariance was established, indicating that participants from Poland and the United States understood trust in the same way, and moreover, the strength of the factor loadings of Trust could be deemed equivalent. However, we failed to establish full scalar invariance, which suggested that the intercepts of the compared groups were not equal and thus, comparing their latent means would be inappropriate. Through inspection of the modification indices we assessed which intercepts were the source of the lack of scalar invariance, and two items (i.e., Items 1 "Most people are basically honest" and 6 "Generally, I trust others") were found to be problematic. When the constraints of these two intercepts were freed, the change in the fit indices was low. Thus, partial scalar invariance was established and a cautious latent means comparison became possible. In Table 8 we present a comparison of sample differences in GTS Trust, supplemented with comparisons on the item-level.

The results of the latent mean comparison revealed virtually no differences in trust between Poland and the United States; however, there were two differences in contradictory directions found in item-level analysis. The differences were

Table 5 Descriptive statistics and bivariate correlations

\begin{tabular}{llll}
\hline & 1. & $M$ & $S D$ \\
\hline 1. Trust & & $3.15 \mid 3.09$ & $0.69 \mid 0.68$ \\
2. Happiness & $.21 * \mid .31 * *$ & $5.05 \mid 4.67$ & $1.10 \mid 1.10$ \\
\hline
\end{tabular}

American sample listed first

$* p<.01 ; * * p<.001$ for the two items that were the cause of the lack of scalar invariance, i.e., Americans scored higher on t1 whereas Poles scored lower on $\mathrm{t} 6$.

In sum, these results generally confirm our expectations regarding the structure of the GTS. Our findings verify the same unidimensional structure across two different cultures. While we did not find any differences in levels of GTS Trust for these two samples (Hypothesis 4 was not confirmed), contradictory results on the item-level may account for this lack of differences.

\section{Test of the Hypothesis Regarding Differences in the Level of Happiness}

To assess the differences in the level of happiness between Americans and Poles, a MGCFA was conducted, and these results are presented in Table 9.

All of the analyzed models were well-fitted to the data, however, the difference between the configural and metric model exceeded acceptable values, suggesting that latent mean could be untrustworthy. Thus, we applied an alignment optimization, which analyzes the invariance of all parameters (i.e., loadings and intercepts) between the analyzed groups. If the absolute number of non-invariant parameters do not exceed $25 \%$, latent means can be assumed to be trustworthy (Cieciuch et al. 2018; Muthén and Asparouhov 2014). The results revealed that the source of the lack of invariance were the intercepts of Item 4, which were non-invariant in both groups. Thus, the total number of non-invariant parameters did not exceed $25 \%$, and the latent means could be compared. In reference to the American sample, for which the latent mean was fixed to 0 , Poles scored significantly lower $(M=$ $-.42 ; p<.05)$, confirming the fifth hypothesis.

\section{Test of the Hypothesis Regarding the Relation between Trust and Happiness}

Hypothesis 6 assumed that trust would be linked to level of happiness, and that the relation between these two variables would be positive and similar in strength for both countries. Two independent SEM models were conducted to test this hypothesis; these results are shown in Table 10. 
The analyzed SEM models were both well-fitted to the data. The results of the structural part of the models revealed that trust positively predicts level of happiness in both Poland and the United States. The difference in strength of these estimates turned out to be non-significant $(Z=0.58 ; p=.280)$ supporting the last hypothesis.

\section{Discussion}

The second study was conducted to verify whether the structure of GTS would remain the same in samples from two distinct cultures. We expected that Americans would be more trusting and happier than Poles, but at the same time, the link between happiness and trust would be positive and similar in strength in these two countries. As expected, Americans demonstrated higher level of happiness than Poles. This finding is consistent with the results of the global happiness reports (Helliwell et al. 2016; Helliwell et al. 2018) and may be understand as a consequence of differences in self-construal in these two countries (the US is a more individualistic country and individualism is a strong determinant of happiness). However, analyses did not show any significant differences in the generalized level of trust across these two samples. Item analysis revealed some sample differences that were obscured when the total score was used. Specifically, Poles, compared to Americans, showed higher levels of agreement with the statement that most people are honest. At the same time, they declared that in general, they were less eager to trust others than Americans. The first result might be reflective of patterns in global surveys showing a significant increase in general trust in Poland and a big decrease in United States in the last year (although US still scores higher on the trust dimension; Edelman 2018), indicating patterns of change in perceptions regarding trust in Poland. With regard to the second finding, Poland is a more particularistic and collectivist society than the U.S. (Hofstede 2001; Trompenaars and Hampden-Turner 2011). Collectivist societies, which place great value on ingroup members, can create mistrust towards out-group members (Hofstede 2001; Smith et al. 1997). Therefore, people

Table 6 Standardized factor loadings of the General Trust Scale in Poland and the United States

\begin{tabular}{llllll}
\hline & \multicolumn{2}{l}{ Poland } & & & \multicolumn{2}{l}{ United States } \\
\cline { 2 - 3 } \cline { 5 - 6 } & Trust & Method factor & & Trust & Method factor \\
\hline $\mathrm{t} 1$ & .81 & .30 & .55 & .56 \\
$\mathrm{t} 2$ & .82 & .32 & .69 & .52 \\
$\mathrm{t} 3$ & .31 & .37 & .17 & .53 \\
$\mathrm{t} 4$ & .66 & .34 & .34 & .60 \\
$\mathrm{t} 5$ & .20 & .35 & .26 & .52 \\
$\mathrm{t} 6$ & .60 & .29 & .43 & .50 \\
\hline
\end{tabular}

Table 7 Results of the multigroup confirmatory factor analysis comparing the structure of trust in Poland and the United States

\begin{tabular}{llll}
\hline & $\chi_{(\mathrm{df})}^{2}$ & CFI & RMSEA \\
\hline Configural & $28.12_{(16)}$ & .983 & .059 \\
Metric & $33.07_{(21)}$ & .983 & .052 \\
Scalar & $57.92_{(25)}$ & .954 & .078 \\
Partial scalar* & $35.32_{(23)}$ & .983 & .050 \\
Metric vs configural & $4.95_{(5)}$ & .000 & .007 \\
Scalar vs metric & $24.85_{(4)}$ & .029 & .026 \\
Partial scalar vs metric & $2,25_{(2)}$ & .000 & .002 \\
\hline
\end{tabular}

* Intercepts of Items 1 and 6 were freed

from collectivist countries may be more cautious than those from more individualistic countries in trusting others.

Consistent with our expectations and the results of previous studies (Jasielska 2018; Rothstein and Uslaner 2005; Tov and Diener 2008), trust predicted levels of happiness. As expected, the strength of this relationship was similar in Poland and the United States. These findings provide further evidence of convergent validity and preliminary confirmation for the external validity of the GTS for use for cross-cultural research in North America and Europe.

\section{General Discussion}

In the quest for improved understanding of cross-cultural variations in trust, measures of trust with established crosscultural validity become critical. We conducted two studies in order to evaluate and compare the structure and validity of the GTS scale in European (Polish) and US populations. The GTS showed expected patterns of convergent validity in the Polish sample. Furthermore, when responses to the GTS from a U.S and a Polish sample (e.g., an individualistic and a more collectivist culture) were compared, levels of trust were similar in both cultures, and trust was similarly positively predictive of happiness. However, results from both studies suggest that attention to GTS item analyses may be warranted, both from the standpoint of understanding the psychometrics

Table 8 Comparison in latent mean of Trust and the item-level differences between Poland and the United States

\begin{tabular}{llll}
\hline & $M_{P L}$ & $M_{U S}$ & $F / t$ \\
\hline Trust & 0.00 & -.14 & 0.91 \\
$\mathrm{t} 1$ & 3.02 & 2.81 & $2.33^{*}$ \\
$\mathrm{t} 2$ & 2.81 & 2.81 & 0.06 \\
$\mathrm{t} 3$ & 3.60 & 3.73 & 1.69 \\
$\mathrm{t} 4$ & 3.13 & 3.24 & 1.27 \\
$\mathrm{t} 5$ & 2.88 & 2.90 & 0.31 \\
$\mathrm{t} 6$ & 3.12 & 3.38 & $2.59^{*}$ \\
\hline
\end{tabular}


Table 9 Results of the multigroup confirmatory factor analysis comparing the structure of happiness in Poland and the United States

\begin{tabular}{llll}
\hline & $\chi_{(\mathrm{df})}^{2}$ & CFI & RMSEA \\
\hline Configural & $4.28_{(4)}$ & 1.00 & .018 \\
Metric & $32.78_{(7)}$ & .958 & .130 \\
Scalar & $42.55_{(10)}$ & .948 & .122 \\
Metric vs configural & $28.5_{(3)}$ & 0.42 & .112 \\
Scalar vs metric & $9.77_{(3)}$ & .010 & .008 \\
\hline
\end{tabular}

of this scale, and from the standpoint of gaining a better understanding of cross-cultural variations in responding.

Item analysis yielded some potentially interesting crosscultural differences in trust between the U.S. and Poland. Specifically, when respondents were queried about perceptions of honesty of individual people and willingness to trust in the society, Polish and American young adults differed, with Americans showing greater willingness to trust in a society. Fukuyama (2001) notes that in collectivistic societies, ingroup solidarity and the ability to cooperate collectively with the in-group reduces the tendency for such behavior with outsiders, and often inflicts negative perceptions of the qualities of outsiders. Basically, a society that values and trusts in-group members can create mistrust towards out-group members (Hofstede 2001; Smith et al. 1996). Because Poland is generally a more collectivist culture than the US, this may explain some of the differences in responding when questions focus on willingness to trust in society, in general.

Our study has several limitations. In current studies backtranslations of the measures from Polish to English and Japanese involved only one person. In future research, it would be advisable to verify them by employing more translators. What is more, the samples are unlikely to be fully representative of the population of the respective countries, since it is likely that study respondents were somewhat more well-educated, more technologically savvy, and of a higher socioeconomic status than the average citizen. Additionally the genders and ages of the US and Polish respondents in this two country comparison differed, and this may have introduced some artifacts in our findings. Finally, while Poland and the US differ culturally, Poland is not as collectivist as many Eastern countries (e.g., Hofstede 2001). Thus, the validity of the GTS in cultures which vary significantly from those of the US and Poland still warrants further investigation.

Table 10 Summary of model fit statistics of the tested models and the standardized estimates of the structural part in which trust predicted level of happiness

\begin{tabular}{lllll}
\hline & $\chi_{(\mathrm{df})}^{2}$ & CFI & RMSEA & $\beta$ \\
\hline Poland & $57.53_{(34)}$ & .966 & .058 & .36 \\
United States & $69.71_{(34)}$ & .957 & .068 & .31 \\
\hline
\end{tabular}

The future research should continue to develop the measure by testing invariance on larger and more representative samples.

In spite of this, these two studies provide preliminary support for the use of the GTS for measurement and cross-cultural comparison of trust. Future studies might continue to explore the role that social connectedness and in-group, out-group status play in influencing trust, and particularly, the differential impacts of connectedness and group membership for cross cultural variations in trust (e.g., Yuki et al. 2005). Given that trust appears to increase with age, and that older adults may rely on trust for social connectedness (e.g., Li and Fung 2012), use of the GTS cross culturally might elucidate interesting and culturally unique processes in the evolution of trust across the lifespan. Finally, given recent worldwide trends toward nationalism, examination of the role of that trust towards ingroup and out-group members may play in the strengthening of nationalistic values warrants investigation.

\section{Implications}

Our study results have implications on at least two levels. The first is related to studies in psychology, and especially, to cross-cultural comparisons. While simple analysis of mean trust between these two countries revealed no differences, more detailed consideration revealed that Americans and Poles differ in particular aspects of trust that may have implications for understanding of variance in trust as it manifests in social and cultural contexts. These findings suggest that future cross cultural research on trust may benefit from movement beyond global considerations to investigation of some of the more detailed processes and mechanisms that may account for variability in trust in situational contexts. The result might be a more indigenous psychological perspective in which both the content and the context of research are more fully considered (Allwood and Berry 2006). For example, although scientists frequently acknowledge culture as a source of influence on human behavior, there still has been little attention to psychological theories or data from many cultures, including Latin America, Africa and South-East Asia.

The second implication is much broader and relates to recent increases in patterns of migration worldwide. Social connection and social support are key components of subjective well being (Wang 2016), and as such, they contribute in an important way to resilience under conditions of stress (Pietrzak et al. 2010) and to a healthy and happy life (HoltLunstad et al. 2017). However, the social interactions that form the basis for these social connections must be derive from a foundation of trust. Our data suggest that trust itself may be significantly influenced by fundamental convictions about interactions with others that derive as a function of sociocultural history, norms, beliefs and value systems. When cultures collide, as they have in current ongoing migrant waves, increased 
understanding and sensitivity to cross cultural features of trust and social relatedness may particularly benefit interventionists working with migrant populations. This information has relevance for both building successful interpersonal relations in the process of integration (Ward and Rana-Deuba 1999; Ward et al. 2001), and for facilitating a broader climate of cross cultural understanding and social connection for those for whom social integration and support can be critical.

Acknowledgments The work of Dorota Jasielska was supported by the Maria Grzegorzewska University grant [grant number BSTP 27/17-I]. The work of Radosław Rogoza was supported by National Science Centre, Poland [grant number 2017/26/E/HS6/00282]. Data are available from the authors upon reasonable request.

Data Availability The datasets during and/or analyzed during the current study available from the corresponding author on reasonable request.

\section{Compliance with Ethical Standards}

Ethical Approval All procedures performed in studies involving human participants were in accordance with the ethical standards of the institutional and/or national research committee and with the 1964 Helsinki declaration and its later amendments or comparable ethical standards.

Informed Consent Informed consent was obtained from all individual participants included in the study.

Conflict of Interest On behalf of all authors, the corresponding author states that there is no conflict of interest.

Open Access This article is distributed under the terms of the Creative Commons Attribution 4.0 International License (http:// creativecommons.org/licenses/by/4.0/), which permits unrestricted use, distribution, and reproduction in any medium, provided you give appropriate credit to the original author(s) and the source, provide a link to the Creative Commons license, and indicate if changes were made.

\section{References}

Allwood, C. M., \& Berry, J. W. (2006). Origins and development of indigenous psychologies: An international analysis. International Journal of Psychology, 41(4), 243-268.

Ashraf, N., Bohnet, I., \& Piankov, N. (2006). Decomposing trust and trustworthiness. Experimental Economics, 9, 193-208.

Basabe, N., \& Ros, M. (2005). Cultural dimensions and social behavior correlates: Individualism-collectivism and power distance. International Review of Social Psychology, 18, 189-225.

Bohnet, I., \& Zeckhauser, R. (2004). Trust, risk and betrayal. Journal of Economic Behavior and Organization, 55, 467-484.

Butler, J. V., Giuliano, P., \& Guiso, L. (2016). Trust and cheating. The Economic Journal, 126, 1703-1738.

Byrne, B. M. (1994). Structural equation modeling with EQS and EQS/ windows. Thousand Oaks, CA: Sage Publications.

Carter, N. L., \& Mark Weber, J. (2010). Not Pollyannas: Higher generalized trust predicts lie detection ability. Social Psychological and Personality Science, 1, 274-279.

Chen, F. F. (2007). Sensitivity of goodness of fit indexes to lack of measurement invariance. Structural Equation Modeling, 14, 464-504.
Cieciuch, J., Davidov, E., \& Schmidt, P. (2018). Alignment optimization: Estimation of the most trustworthy means in cross-cultural studies even in the presence of noninvariance. In E. Davidov, P. Schmidt, J. Billiet, \& B. Meuleman (Eds.), Cross-cultural analysis: Methods and applications. New York, NY: Routledge.

Czapinski, J., and Panek, T. (Ed.) (2015). Social diagnosis. Retrieved from: https://www.diagnoza.com [accessed 10.09.2018].

Delhey, J., \& Newton, K. (2005). Predicting cross-national levels of social trust: Global pattern or Nordic exceptionalism? European Sociological Review, 21, 311-327.

Delhey, J., Newton, K., \& Welzel, C. (2011). How general is trust in Bmost people $^{\wedge}$ ? Solving the radius of trust problem. American Sociological Review, 76(5), 786-807.

Diener, E., Diener, M., \& Diener, C. (1995). Factors predicting the subjective well-being of nations. Journal of Personality and Social Psychology, 69, 851-864.

Digman, J. M. (1990). Personality structure: Emergence of the five-factor model. Annual Review of Psychology, 41, 417-440.

Edelman, R. (2018) Edelman trust barometer 2018. Retrieved from: https://www.edelman.com/trust-barometer/ [accessed 8.09.2018].

Evans, A. M., \& Revelle, W. (2008). Survey and behavioral measurements of interpersonal trust. Journal of Research in Personality, 42, $1585-1593$.

Fernández, I., Paez, D., \& González, J. L. (2005). Independent and interdependent self-construals and socio-cultural factors in 29 nations. Revue Internationale de Psychologie Sociale, 18, 35-63.

Fukuyama, F. (1995). Trust: The social virtues and the creation of prosperity (no. D10 301 c. 1/c. 2). Free press paperbacks.

Fukuyama, F. (2001). Social capital, civil society and development. Third World Quarterly, 22, 7-20. https://faculty.uml.edu/sgallagher/ Trump Populism Norris.pdf [accessed 14.11.2018].

Glaeser, E. L., Laibson, D. I., Scheinkman, J. A., \& Soutter, C. L. (2000). Measuring trust. The Quarterly Journal of Economics, 115, 811846.

Goldberg, L. R. (1990). An alternative" description of personality": The big-five factor structure. Journal of Personality and Social Psychology, 59(6), 1216-1229.

Gosling, S. D., Rentfrow, P. J., \& Swann, W. B., Jr. (2003). A very brief measure of the big-five personality domains. Journal of Research in Personality, 37(6), 504-528.

Growiec, K., \& Growiec, J. (2014). Trusting only whom you know, knowing only whom you trust: The joint impact of social capital and trust on happiness in CEE countries. Journal of Happiness Studies, 15, 1015-1040.

Hampden-Turner, C., \& Trompenaars, F. (1997). Mastering the infinite game: How east Asian values are transforming business practices. Oxford: Capstone.

Helliwell, J. F. (2006). Well-being, social capital and public policy: What's new? The Economic Journal, 116, 34- 45.

Helliwell, J., Huang, H., \& Wang, S. (2016). The distribution of the world happiness. In J. Helliwell, R. Layard, \& G. Sachs (Eds.), World happiness report 2016 (pp. 8-49). New York: Sustainable Development Solutions Network.

Helliwell, J., Layard, R., \& Sachs, J. (2018). World happiness report 2018. New York: Sustainable Development Solutions Network.

Hofstede, G. (2001). Culture's consequences: Comparing values, behaviors, institutions and organizations across nations. Sage publications.

Holt-Lunstad, J., Robles, T. F., \& Sbarra, D. A. (2017). Advancing social connection as a public health priority in the United States. American Psychologist, 72, 517-530.

Huff, L., \& Kelley, L. (2005). Is collectivism a liability? The impact of culture on organizational trust and customer orientation: A sevennation study. Journal of Business Research, 58(1), 96-102.

Inglehart, R., and Norris, P. (2016). Trump, Brexit, and the rise of populism: Economic have-nots and cultural backlash. Retrieved from: 
https://faculty.uml.edu/sgallagher/Trump_Populism_Norris.pdf [accessed 14.09.2018].

Jasielska, D. (2018). The moderating role of kindness on the relation between trust and happiness. Current Psychology, Advance online publication, 1-9.

Johnson, N. D., \& Mislin, A. A. (2011). Trust games: A meta-analysis. Journal of Economic Psychology, 32, 865-889.

Li, T., \& Fung, H. H. (2012). Age differences in trust: An investigation across 38 countries. Journals of Gerontology Series B: Psychological Sciences and Social Sciences, 68(3), 347-355.

Lyubomirsky, S., \& Lepper, H. S. (1999). A measure of subjective happiness. Preliminary reliability and construct validation. Social Indicators Research, 46, 137-155.

Maddux, W. W., \& Brewer, M. B. (2005). Gender differences in the relational and collective bases for trust. Group Processes \& Intergroup Relations, 8, 159-171.

Markus, H. R., \& Kitayama, S. (1991). Culture and the self: Implications for cognition, emotion, and motivation. Psychological Review, 98, 224-253.

Mayer, R. C., Davis, J. H., \& Schoorman, F. D. (1995). An integrative model of organizational trust. Academy of Management Review, 20 , 709-734.

McCrae, R. R. (2004). Human nature and culture: A trait perspective. Journal of Research in Personality, 38(1), 3-14.

McCrae, R. R., \& Terracciano, A. (2005). Personality profiles of cultures: Aggregate personality traits. Journal of Personality and Social Psychology, 89(3), 407.

Montoro, A., Shih, P. C., Román, M., \& Martínez-Molina, A. (2014). Spanish adaptation of Yamagishi general trust scale. Anales de Psicología/Annals of Psychology, 30, 302-307.

Mungiu-Pippidi, A. Dadašov, R., and Fazekas, M. (2015). Public Integrity and Trust in Europe. Retrieved from: https://www. government.nl/documents/reports/2016/01/18/public-integrity-andtrust-in-europe [accessed 8.11.2018].

Muthén, L., and Muthén, B. O. (2012). Mplus User's Guide, 6th Edn. Los Angeles, CA: Mutheìn \& Mutheìn.

Muthén, B., \& Asparouhov, T. (2014). IRT studies of many groups: The alignment method. Frontiers in Psychology, 5, 978.

Pietrzak, R. H., Johnson, D. C., Goldstein, M. B., Malley, J. C., Rivers, A. J., Morgan, C. A., \& Southwick, S. M. (2010). Psychosocial buffers of traumatic stress, depressive symptoms, and psychosocial difficulties in veterans of operations enduring freedom and Iraqi freedom: The role of resilience, unit support, and postdeployment social support. Journal of Affective Disorders, 120, 188-192.

Podsakoff, P. M., MacKenzie, S. B., \& Podsakoff, N. P. (2012). Sources of method bias in social science research and recommendations on how to control it. Annual Review of Psychology, 63, 539-569.

Putnam, R. D. (2000). Bowling alone: America's declining social capital. In L. Crothers \& C. Lockhart (Eds.), Culture and politics (pp. 223 234). New York: Palgrave Macmillan.

Realo, A., Allik, J., \& Greenfield, B. (2008). Radius of trust: Social capital in relation to familism and institutional collectivism. Journal of Cross-Cultural Psychology, 39(4), 447-462.

Rothstein, B., \& Uslaner, E. M. (2005). All for all: Equality, corruption, and social trust. World Politics, 58, 41-72.

Rotter, J. B. (1967). A new scale for the measurement of interpersonal trust. Journal of Personality, 35(4), 651-665.

Rotter, J. B. (1971). Generalized expectancies for interpersonal trust. American Psychologist, 26(5), 443-452.
Schwartz, S. H. (1994). Are there universal aspects in the structure and contents of human values? Journal of Social Issues, 50, 19-45.

Schwartz, S. (2006). A theory of cultural value orientations: Explication and applications. Comparative Sociology, 5(2-3), 137-182.

Sharkey, W. F., \& Singelis, T. M. (1995). Embarrassability and self-construal: A theoretical integration. Personality and Individual Differences, 19, 919-926.

Singelis, T. M., \& Sharkey, W. F. (1995). Culture, self-construal, and embarrassability. Journal of Cross-Cultural Psychology, 26, 622-644.

Smith, P. B., Dugan, S., \& Trompenaars, F. (1996). National culture and the values of organizational employees: A dimensional analysis across 43 nations. Journal of Cross-Cultural Psychology, 27(2), 231-264

Smith, P. B., Dugan, S., \& Trompenaars, F. (1997). Locus of control and affectivity by gender and occupational status: A 14 nation study. Sex Roles, 36, 51-77.

Soto, C. J., \& John, O. P. (2017). The next big five inventory (BFI-2): Developing and assessing a hierarchical model with 15 facets to enhance bandwidth, fidelity, and predictive power. Journal of Personality and Social Psychology, 113, 117-143.

Sztompka, P. (1996). Trust and emerging democracy: Lessons from Poland. International Sociology, 11, 37-62.

Tov, W., \& Diener, E. (2008). The well-being of nations: Linking together trust, cooperation, and democracy. In B. A. Sullivan, M. Snyder, \& J. L. Sullivan (Eds.), Cooperation: The political psychology of effective human interaction (pp. 323-342). Malden, MA: Blackwell.

Triandis, H. C. (2000). Cultural syndromes and subjective well-being. In E. Diener \& E. M. Suh (Eds.), Culture and subjective well-being (pp. 13-36). Cambridge, MA: The MIT Press.

Trompenaars, F., \& Hampden-Turner, C. (2011). Riding the waves of culture: Understanding diversity in global business. London: Nicholas Brealey International.

Wang, X. (2016). Subjective well-being associated with size of social network and social support of elderly. Journal of Health Psychology, 21, 1037-1042.

Ward, C., \& Rana-Deuba, A. (1999). Acculturation and adaptation revisited. Journal of Cross-Cultural Psychology, 30, 372-392.

Ward, C. A., Bochner, S., \& Furnham, A. (2001). The psychology of culture shock (2nd ed.). Hove, UK: Routledge.

Wright, R. (2000). Nonzero: The logic of human destiny. New York: Pantheon Books.

Yamagishi, T., \& Kosugi, M. (1999). Cheater detection in social exchange. Cognitive Studies, 6, 179-190.

Yamagishi, T., \& Yamagishi, M. (1994). Trust and commitment in the United States and Japan. Motivation and Emotion, 18, 129-166.

Yamagishi, T., Kikuchi, M., Kosugi, M. (1999). Trust, gullibility and social intelligence. Asian Journal of Social Psychology, 2, 145-161.

Yamagishi, T. (2001). Trust as a form of social intelligence. In K. S. Cook (Ed.), Trust in society (pp. 121-147). New York: Russell Sage.

Yuki, M., Maddux, W. W., Brewer, M. B., \& Takemura, K. (2005). Crosscultural differences in relationship- and group-based trust. Society for Personality and Social Psychology, 31, 48-62.

Zajenkowska, A., Zimmerman, M., \& J. (2013). Relative culture: A study on contexting and extraversion among American and polish expatriates. Baltic Journal of Management, 9, 2-21.

Publisher's note Springer Nature remains neutral with regard to jurisdictional claims in published maps and institutional affiliations. 